\title{
Workplace Violence Against Health Care Providers In Alexandria University Hospitals, Egypt.
}

\author{
${ }^{1}$ Andrew Malak Michael, ${ }^{1}$ Soha Rashed, ${ }^{2}$ Asmaa Mohamed Elkafafy, ${ }^{1}$ Eman Anwar \\ Sultan
}

${ }^{1}$ Department of Community Medicine, ${ }^{2}$ Department of Emergency Medicine,Faculty of Medicine, Alexandria University

\begin{abstract}
Background: Workplace violence (WPV) is a major public health problem worldwide. Although workers in different occupations are at risk of exposure to WPV, health care workers and particularly those working in emergency departments are at increasing risk. Limited research, together with under-estimated magnitude due to underreporting of incidents and the substantial consequences on healthcare delivery, organizations and society in general create an urgent need to target WPV by research. Objectives: to determine prevalence, types, perpetrators, consequences and reporting pattern of WPV among physicians and nurses in emergency care units in Alexandria University Hospitals. Method: A cross-sectional study was conducted among HCWs to assess WPV in the studied settings. 113 nurses and 81 doctors were interviewed over a three-month period using an adapted form of Workplace Violence in the Health Sector Survey Interviewing Questionnaire. Results: prevalence of WPV was $91.7 \%$ with psychological abuse being the most common form followed by physical aggression and sexual harassment $(87.6 \%, 49.5 \%$ and $12.4 \%$ respectively). Patients' relatives were the most common perpetrators of WPV followed by patients themselves. Moreover, most of victims showed symptoms of Post-incident distress such as recalling memories of the incident, avoiding to talk about it and being super-alert. Most of incidents were underreported with physical incidents showing the highest reporting rate $(32.3 \%)$ compared to incidents of psychological abuse $(16.2 \%)$, while incidents of sexual harassment were never reported. The most common incriminated factors were ineffective security measures, work overload and overcrowding, improper patient attitudes and shortage of staff and resources. Conclusions: WPV is a serious problem in the studied settings and this makes them in urgent need for effective interventions. Reducing incidents of WPV requires integration between multiple sectors rather than relying on a single intervention. The most common recommended measures were application of effective security measures, increasing number of staff and usage of standard protocols and policies against WPV.
\end{abstract}

Key words: workplace violence, emergency, healthcare workers, Alexandria.

Corresponding author: Andrew Malak Tawfik Michael E-mail: drandrewmalakmichael@ gmail.com

\section{Introduction}

Workplace violence (WPV) is a major public health problem that has received growing attention worldwide. ${ }^{1}$ It is defined by the World Health Organization (WHO) as "Incidents where staff are abused, threatened or assaulted in circumstances related to their work, including commuting to and from work, involving an explicit or implicit challenge to their safety, well-being or health"2 WPV is a striking phenomenon that has much increased in the last few years. In fact, it coincides with the escalation of violence in different fields of social life which has been reflected on workers and workplace environment. ${ }^{3}$ Although most 
people perceive the concept of workplace violence as physical aggression, it is not only restricted to the physical type. It can be divided into physical, psychological and sexual violence. ${ }^{4}$

Although all workers in different occupations are at risk of exposure to WPV, health care workers (HCWs) in particular are at increasing risk of WPV compared to other occupations. The WHO reported that between $8 \%$ and $38 \%$ of health workers suffer physical violence at some point in their careers. ${ }^{5}$ Nationally, a study carried out in Suez Canal University Hospital revealed that $59.7 \%$ of HCWs were victims of WPV. ${ }^{6}$ In Alexandria, another study was conducted among nurses in the main university hospital and it revealed that $87.1 \%$ of nurses experienced psychological WPV. ${ }^{7}$

Among HCWs in different health care settings, those working in emergency departments are highly exposed to WPV compared to other HCWs. The American College of Emergency Physicians (ACEP) stated that $75 \%$ of physicians working in emergency settings were exposed to at least one incident of WPV in the preceding year. ${ }^{8}$ Moreover, in 2011, another survey was conducted among nurses in the United States and this study noted that $54.5 \%$ of nurses working in emergency settings had experienced at least one incident of physical or nonphysical WPV during the week before conduction of the study. ${ }^{9}$ Patients and their relatives are the most common type of perpetrators of such incidents. ${ }^{10}$

There are several adverse events following exposure of HCWs to WPV in health care settings. One of the most common problems HCWs suffer from is post-traumatic stress disorder (PTSD). ${ }^{11}$ In fact, psychological and emotional consequences are more common and have deeper influence on HCWs than physical injuries. $^{12}$ However, consequences of WPV extend beyond the HCWs to affect the quality and process of health care delivery. ${ }^{13}$ Effective management of incidents of WPV at workplace requires a long-term holistic strategic approach. Raising awareness, training courses and involvement of health care personnel and community gate keepers are key elements in tackling the rising epidemic of WPV together with strict policies and laws and improvement of infrastructure. ${ }^{14}$

In Alexandria, few studies have been carried out and research in emergency settings is much scarcer. Therefore, limited research, together with underestimated magnitude due to underreporting of incidents, the wellestablished substantial consequences on HCWs, healthcare delivery, organizations and society in general and the very huge population served by the emergency units in Alexandria University Hospitals, create an urgent need to target WPV by research. The study aimed to investigate the occurrence of workplace violence (Prevalence, types, perpetrators, consequences and reporting pattern) among physicians and nurses in emergency care units in Alexandria University Hospitals.

\section{Method}

A cross-sectional study was conducted among HCWs in the emergency care unit in Alexandria Main University Hospital and in the trauma unit in El Hadara University Hospital to assess WPV in the studied settings. All available HCWs were approached with a response rate of $84.3 \%$. The included participants (113 nurses and 81 doctors) belonged to emergency, surgery and orthopedics departments.

The included participants were interviewed over a three-month period; May to July 2018, using an adapted form of Workplace Violence in the Health Sector Survey Interviewing Questionnaire $^{15}$ that was developed through collaborations between WHO, International Labour Office (ILO), International Council of Nurses (ICN) and Public Services International (PCI). It inquired about personal and occupational 
Table 1: Socio-demographic characteristics and workplace of the included participants.

\begin{tabular}{|c|c|c|c|c|c|c|}
\hline \multirow{2}{*}{ Personal data } & \multicolumn{2}{|c|}{$\begin{array}{c}\text { Nurses } \\
(n=113)\end{array}$} & \multicolumn{2}{|c|}{$\begin{array}{c}\text { Doctors } \\
(n=81)\end{array}$} & \multicolumn{2}{|c|}{$\begin{array}{c}\text { Total } \\
(n=194)\end{array}$} \\
\hline & $\mathbf{N}$ & $\%$ & $\mathbf{N}$ & $\%$ & $\mathbf{N}$ & $\%$ \\
\hline \multicolumn{7}{|l|}{ Age (years) } \\
\hline $20-30$ & 15 & 13.3 & 73 & 90.1 & 88 & 45.4 \\
\hline $31-40$ & 32 & 28.3 & 8 & 9.9 & 40 & 20.6 \\
\hline $41-50$ & 48 & 42.5 & & & 48 & 24.7 \\
\hline $51-60$ & 18 & 15.9 & & & 18 & 9.3 \\
\hline Min-max & \multirow{2}{*}{\multicolumn{6}{|c|}{$\begin{array}{c}25-57 \\
8 \pm 9.2 \text { years }\end{array}$}} \\
\hline mean $\pm \mathrm{SD}$ & & & & & & \\
\hline \multicolumn{7}{|l|}{ Gender } \\
\hline Male & 10 & 8.8 & 68 & 84.0 & 78 & 40.2 \\
\hline Female & 103 & 91.2 & 13 & 16.0 & 116 & 59.8 \\
\hline \multicolumn{7}{|l|}{ Department/unit } \\
\hline Emergency (ER) & 96 & 85.0 & 21 & 26.0 & 117 & 60.3 \\
\hline Plastic surgery & 0 & 0 & 8 & 10.0 & 8 & 4.1 \\
\hline Oncology & 0 & 0 & 7 & 8.6 & 7 & 3.6 \\
\hline Colorectal & 0 & 0 & 6 & 7.4 & 6 & 3.1 \\
\hline Head and neck & 0 & 0 & 6 & 7.4 & 6 & 3.1 \\
\hline Hepatobiliary & 0 & 0 & 7 & 8.6 & 7 & 3.6 \\
\hline GIT & 0 & 0 & 6 & 7.4 & 6 & 3.1 \\
\hline Specialities & 0 & 0 & 7 & 8.6 & 7 & 3.6 \\
\hline Orthopedics & 17 & 15.0 & 13 & 16.0 & 30 & 15.5 \\
\hline
\end{tabular}

data of HCWs, experiences of different types of WPV, characteristics of workplace environment and opinions of included participants about causes and recommended measures against WPV.

The collected data were revised and coded. Then, data were fed to the computer using Statistical Package for Social Science (SPSS) program (version 22.0). Appropriate descriptive and inferential statistical analyses were done. Prevalence, percentages, arithmetic mean and standard deviation were calculated to describe socio-demographic characteristics of respondents, their occupational characteristics, and assessments of different types of WPV they were exposed to. Chi-square, Fisher's Exact and Monte Carlo tests were performed to compare between categorical variables. A 5\% level of significance was selected for this study.

\section{Ethical Consideration}

Objectives of the study, the expected benefits, and types of information to be obtained were explained to the health care staff to get their informed consent. The proposal was submitted to the Research Ethics Committee at the Alexandria Faculty of Medicine and it gained approval. Informed consents (both written and verbal) were obtained from the included participants and privacy and confidentiality of data were ensured.

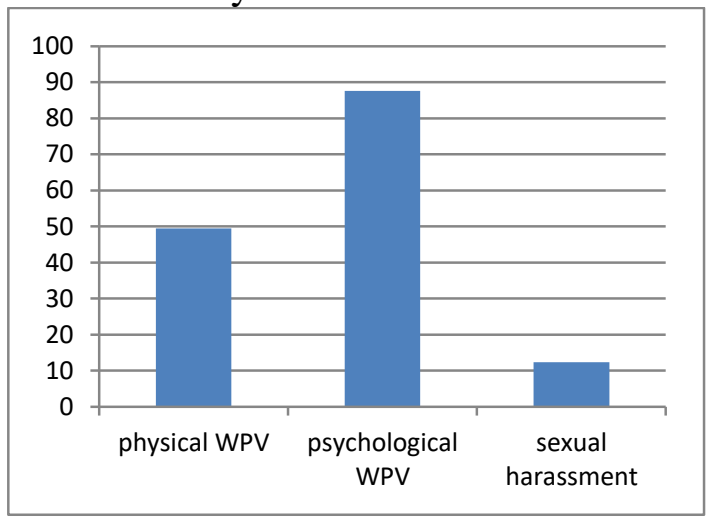

Figure 1: Prevalence of WPV in the studied settings.

\section{Results}

The current study included 194 participants. About three fifths (58.25\%) of them were nurses and $41.75 \%$ were doctors. Age of participants ranged from 25 years to 57 years, with a mean of 
Table 2: Characteristics of WPV in the studied settings.

\begin{tabular}{|c|c|c|c|c|c|c|}
\hline & \multicolumn{2}{|c|}{ Physical WPV } & \multicolumn{2}{|c|}{ Psychological WPV } & \multicolumn{2}{|c|}{ Sexual harassment } \\
\hline & $\mathrm{N}=96$ & $\%$ & $\mathrm{~N}=170$ & $\%$ & $\mathrm{~N}=24$ & $\%$ \\
\hline \multicolumn{7}{|l|}{ Perpetrators } \\
\hline Patient & 27 & 28.1 & 68 & 40.0 & 13 & 54.2 \\
\hline Relative & 65 & 67.7 & 97 & 57.1 & 11 & 45.8 \\
\hline Staff member & 2 & 2.1 & 4 & 2.4 & 0 & 0 \\
\hline General public & 2 & 2.1 & 0 & 0 & 0 & 0 \\
\hline Colleague & 0 & 0 & 1 & 0.6 & 0 & 0 \\
\hline Injury & 42 & 43.8 & & & & \\
\hline Treatment & 8 & 17.0 & & & & \\
\hline \multicolumn{7}{|c|}{ Psychological consequences } \\
\hline Memory recall & 52 & 54.2 & 63 & 37.1 & 18 & 75.0 \\
\hline Avoidance & 63 & 65.8 & 64 & 37.6 & 24 & 100 \\
\hline Super-alert & 77 & 80.2 & 145 & 85.3 & 22 & 91.7 \\
\hline Reporting rate & 31 & 32.3 & 28 & 16.2 & & \\
\hline \multicolumn{7}{|l|}{ Causes of underreporting } \\
\hline Not important & 12 & 18.5 & 79 & 56.4 & 8 & 36.4 \\
\hline Ashamed & 5 & 7.7 & 9 & 6.4 & 24 & 100 \\
\hline $\begin{array}{l}\text { Afraid of negative } \\
\text { consequences }\end{array}$ & 25 & 38.5 & 38 & 27.1 & 6 & 27.3 \\
\hline Useless & 60 & 92.3 & 107 & 76.4 & 18 & 81.8 \\
\hline Lack of reporting office & 3 & 4.6 & 25 & 17.9 & 1 & 4.5 \\
\hline
\end{tabular}

Table 3: Opinions of HCWs on factors contributing to physical WPV.

\begin{tabular}{|c|c|c|c|c|c|c|c|}
\hline \multirow{2}{*}{$\begin{array}{c}\text { Factors contributing } \\
\text { to physical WPV }\end{array}$} & \multicolumn{2}{|c|}{$\begin{array}{l}\text { Nurses } \\
\mathrm{N}=113\end{array}$} & \multicolumn{2}{|c|}{$\begin{array}{c}\text { Doctors } \\
\mathrm{N}=81\end{array}$} & \multicolumn{2}{|c|}{$\begin{array}{c}\text { Total } \\
\mathrm{N}=194\end{array}$} & \multirow{2}{*}{$\begin{array}{c}\text { Test of } \\
\text { significance }\end{array}$} \\
\hline & $\mathbf{N}$ & $\%$ & $\mathbf{N}$ & $\%$ & $\mathbf{N}$ & $\%$ & \\
\hline Patients attitudes & 19 & 16.8 & 9 & 11.1 & 28 & 14.3 & $\begin{array}{l}\chi 2=1.243 \\
P=0.265\end{array}$ \\
\hline Work overload & 22 & 19.5 & 15 & 18.5 & 37 & 19.0 & $\begin{array}{l}\chi 2=0.028 \\
P=0.868\end{array}$ \\
\hline Overcrowding & 12 & 10.6 & 5 & 6.2 & 17 & 9.0 & $\begin{array}{l}\chi 2=1.167 \\
\mathrm{P}=0.280\end{array}$ \\
\hline Shortage of staff & 9 & 7.9 & 19 & 23.4 & 28 & 14.3 & $\begin{array}{l}\chi 2=9.16 \\
P=0.002 *\end{array}$ \\
\hline $\begin{array}{l}\text { Ineffective security } \\
\text { measures }\end{array}$ & 30 & 26.7 & 17 & 21.1 & 47 & 24.0 & $\begin{array}{l}\chi 2=0.795 \\
P=0.373\end{array}$ \\
\hline Lack of awareness & 6 & 5.3 & 5 & 6.2 & 11 & 5.7 & $\begin{array}{l}\text { FET }=0.066 \\
P=1.00\end{array}$ \\
\hline Poor management & 5 & 4.4 & 4 & 4.9 & 9 & 4.7 & $\begin{array}{l}\text { FET }=0.028 \\
P=1.00\end{array}$ \\
\hline Shortage of resources & 10 & 8.8 & 7 & 8.6 & 17 & 9.0 & $\begin{array}{l}\chi 2=0.003 \\
P=0.960\end{array}$ \\
\hline
\end{tabular}

2: Chi-Square Test FET: Fisher's Exact Test

$35.8 \pm 9.2$ years, and $45.4 \%$ of them were below 30 years old. As for nurses, mean age was $41.3 \pm 8.4$ years. As for doctors, the mean age was $28.1 \pm 1.8$ years.

More than half of participants $(59.8 \%)$ were females, while $40.2 \%$ were males. Females represented $91.2 \%$ of nurses,
*: Statistically significant while males represented $84 \%$ of doctors included.

About two thirds of participants $(60.3 \%)$ were staff of the emergency department (ER), while $24.2 \%$ belonged to surgery departments/units and the remaining $15.5 \%$ belonged to Orthopedics department. 
Table 4: Opinions of HCWs on factors contributing to psychological WPV.

\begin{tabular}{|c|c|c|c|c|c|c|c|}
\hline \multirow{2}{*}{$\begin{array}{c}\text { Factors } \\
\text { contributing to } \\
\text { psychological } \\
\text { WPV }\end{array}$} & \multicolumn{2}{|c|}{$\begin{array}{l}\text { Nurses } \\
\mathrm{N}=113\end{array}$} & \multicolumn{2}{|c|}{$\begin{array}{c}\begin{array}{c}\text { Doctors } \\
\mathrm{N}=81\end{array} \\
\end{array}$} & \multicolumn{2}{|c|}{$\begin{array}{c}\text { Total } \\
\mathrm{N}=194 \\
\end{array}$} & \multirow{2}{*}{$\begin{array}{c}\text { Test of } \\
\text { significance }\end{array}$} \\
\hline & $\mathbf{N}$ & $\%$ & $\mathbf{N}$ & $\%$ & $\mathbf{N}$ & $\%$ & \\
\hline Patients attitudes & 23 & 20.4 & 10 & 12.3 & 33 & 17.0 & $\begin{array}{l}\chi 2=2.143 \\
P=0.143\end{array}$ \\
\hline Work overload & 18 & 15.9 & 12 & 14.8 & 30 & 15.2 & $\begin{array}{l}\chi 2=0.045 \\
P=0.832\end{array}$ \\
\hline Overcrowding & 19 & 16.9 & 8 & 9.8 & 27 & 13.8 & $\begin{array}{l}\chi 2=1.895 \\
P=0.169\end{array}$ \\
\hline $\begin{array}{l}\text { Absence } \\
\text { psychological } \\
\text { support }\end{array}$ & 13 & 11.4 & 9 & 11.1 & 22 & 11.4 & $\begin{array}{l}\chi 2=0.007 \\
P=0.932\end{array}$ \\
\hline Lack of awareness & 12 & 10.6 & 7 & 8.5 & 19 & 9.7 & $\begin{array}{l}\chi 2=0.209 \\
P=0.648\end{array}$ \\
\hline $\begin{array}{ll}\begin{array}{l}\text { Shortage } \\
\text { resources }\end{array} & \text { of } \\
\end{array}$ & 5 & 4.4 & 7 & 8.6 & 12 & 6.2 & $\begin{array}{l}\chi 2=1.446 \\
\mathrm{P}=0.229\end{array}$ \\
\hline Poor management & 4 & 3.5 & 5 & 6.2 & 9 & 5.3 & $\begin{array}{l}\text { FET }=0.739 \\
\mathrm{P}=0.495\end{array}$ \\
\hline $\begin{array}{l}\text { Ineffective security } \\
\text { measures }\end{array}$ & 19 & 16.9 & 23 & 28.8 & 42 & 21.4 & $\begin{array}{l}\chi 2=3.73 \\
P=0.05^{*}\end{array}$ \\
\hline
\end{tabular}

Х2: Chi-Square Test FET: Fisher's Exact Test

All nurses belonged to ER department $(85 \%)$ and Orthopedics department (15\%). As for doctors, $26 \%$ belonged to ER department, while $58 \%$ of them belonged to surgical departments/units and the remaining doctors (16\%) belonged to Orthopedics department (as shown in table 1).

The current study showed that the overall prevalence of WPV in the studied settings was $91.7 \%$ (figure 1). The prevalence of physical and psychological WPV among the included participants was $49.5 \%$ and $87.6 \%$ respectively. As for sexual harassment, it was estimated to be $12.4 \%$ and it was significantly higher among nurses compared to doctors $\left(\chi^{2}=7.08\right.$; $\left.\mathrm{p}=0.008^{*}\right)$.

As for perpetrators of incidents of WPV, relatives and patients were the main perpetrators of physical WPV in $67.7 \%$ and $28.1 \%$ of incidents respectively. Regarding incidents of psychological violence, relatives were the main perpetrators in $57.1 \%$ of incidents while patients themselves were the perpetrators in $40 \%$ of incidents. As for sexual harassment, patients and their relatives
*: Statistically significant

were the main perpetrators $(54.2 \%$ and $45.8 \%$ respectively (as demonstrated in table 2).

Regarding impact of WPV on included participants, the current study showed that $43.8 \%$ of participants got injured because of the attack, and $17 \%$ of those who got injured required official treatment. As for psychological consequences, nearly half of the victims $(54.2 \%)$ could recall memories of WPV attacks. Nearly two thirds $(65.6 \%)$ of victims tended to avoid mentioning or talking about the attack. Moreover, $80.2 \%$ of victims became super alert in workplace as a response to the attack. Regarding psychological WPV, more than one third of participants(37.1\%) suffered from recalling of memories. Moreover, another one third $(37.6 \%)$ tended to avoid talking about the incidents. Besides, $85.3 \%$ of victims reported being over suspicious (super alert) while being in contact with patients and accompanying relatives to avoid further experience of future incidents. As for sexual harassment, three quarters of victims tended to recall memories of the incident, 
Table 5: Difference between doctors and nurses as regard characteristics of exposure to physical WPV.

\begin{tabular}{|c|c|c|c|c|c|c|c|}
\hline \multirow{2}{*}{$\begin{array}{l}\text { Characteristics } \\
\text { of incidents of } \\
\text { physical WPV }\end{array}$} & \multicolumn{2}{|c|}{$\begin{array}{l}\text { Nurses } \\
(n=60)\end{array}$} & \multicolumn{2}{|c|}{$\begin{array}{c}\text { Doctors } \\
(\mathrm{n}=36)\end{array}$} & \multicolumn{2}{|c|}{$\begin{array}{c}\text { Total } \\
(\mathbf{n}=96)\end{array}$} & \multirow{2}{*}{$\begin{array}{c}\text { Test of } \\
\text { significance }\end{array}$} \\
\hline & $\mathbf{N}$ & $\%$ & $\mathbf{N}$ & $\%$ & $\mathbf{N}$ & $\%$ & \\
\hline \multicolumn{8}{|l|}{ Perpetrators } \\
\hline Patient & 16 & 26.7 & 11 & 30.6 & 27 & 28.1 & $\mathrm{MC}=2.547$ \\
\hline Relative & 40 & 66.7 & 25 & 69.4 & 65 & 67.7 & $\mathrm{P}=0.516$ \\
\hline Staff member & 2 & 3.3 & & & 2 & 2.1 & \\
\hline General public & 2 & 3.3 & & & 2 & 2.1 & \\
\hline Injury & 25 & 41.7 & 17 & 47.2 & 42 & 43.8 & $\begin{array}{l}\chi 2=0.282 \\
P=0.595\end{array}$ \\
\hline Treatment & 4 & 14.8 & 4 & 20.0 & 8 & 17.0 & $\begin{array}{l}\text { FET }=0.219 \\
\mathrm{P}=0.707\end{array}$ \\
\hline \multicolumn{8}{|l|}{ Memories } \\
\hline Yes & 31 & 51.7 & 21 & 58.3 & 52 & 54.2 & $\chi 2=0.403$ \\
\hline No & 29 & 48.3 & 15 & 41.7 & 44 & 45.8 & $\mathrm{P}=0.526$ \\
\hline \multicolumn{8}{|l|}{ Avoidance } \\
\hline Yes & 40 & 66.7 & 23 & 63.9 & 63 & 65.6 & $\chi 2=0.077$ \\
\hline No & 20 & 33.3 & 13 & 36.1 & 33 & 34.4 & $\mathrm{P}=0.781$ \\
\hline \multicolumn{8}{|l|}{ Being super alert } \\
\hline Yes & 46 & 76.7 & 31 & 86.1 & 77 & 80.2 & $\chi 2=1.264$ \\
\hline No & 14 & 23.3 & 5 & 13.9 & 19 & 19.8 & $\mathrm{P}=0.261$ \\
\hline
\end{tabular}

Causes of underreporting

\begin{tabular}{|c|c|c|c|c|c|c|c|}
\hline \multicolumn{8}{|l|}{ Causes of uI } \\
\hline Not important & 8 & 21.1 & 4 & 14.8 & 12 & 18.5 & $\begin{array}{l}\text { FET }=0.408 \\
P=0.747\end{array}$ \\
\hline Ashamed & 2 & 5.3 & 3 & 11.1 & 5 & 7.7 & $\begin{array}{l}\mathrm{FET}=0.760 \\
\mathrm{P}=0.642\end{array}$ \\
\hline $\begin{array}{l}\text { Afraid of } \\
\text { negative } \\
\text { consequences }\end{array}$ & 15 & 39.5 & 10 & 37 & 25 & 38.5 & $\begin{array}{l}\chi 2=0.04 \\
P=0.842\end{array}$ \\
\hline Useless & 36 & 94.7 & 24 & 88.9 & 60 & 92.3 & $\begin{array}{l}\mathrm{FET}=0.760 \\
\mathrm{P}=0.642\end{array}$ \\
\hline $\begin{array}{l}\text { Did not know } \\
\text { who to report to }\end{array}$ & 2 & 5.3 & 1 & 3.7 & 3 & 4.6 & $\begin{array}{l}\mathrm{FET}=0.087 \\
\mathrm{P}=1.00\end{array}$ \\
\hline
\end{tabular}

ఒ2: Chi-Square Test $\quad$ MC: Mont Carlo test

FET: Fisher's Exact Test

Moreover, $18.5 \%$ of victims ignored the

while $91.7 \%$ became over-suspicious.

Moreover, all victims tended to avoid talking about the incident.

Regarding reporting pattern for incidents of WPV, the majority of incidents were not reported. Only $32.3 \%$ of incidents of physical WPV were reported, compared to $16.2 \%$ of incidents of psychological violence, while incidents of sexual harassment were never reported. Causes of underreporting were variable. As for physical WPV, Most of participants felt it is useless to report the incident (92.3\%). Some of the participants were afraid of negative consequences (38.5\%). incident and believed it is not important to report it. Less than one tenth $(7.7 \%)$ of victims felt ashamed to report, and $4.6 \%$ did not know who to report to. As for psychological violence, $76.4 \%$ of victims believed it was useless to report such incidents. Moreover, $56.4 \%$ of incidents were ignored and perceived as not important. Besides, nearly one quarter of participants (27.1\%) did not report as they were afraid of negative consequences. In the remaining incidents, the victims either did not know who to report the incident to $(17.9 \%)$ or felt ashamed to report $(6.4 \%)$. None of incidents of sexual harassment 
Table 6: Difference between doctors and nurses as regard characteristics of exposure to psychological WPV.

\begin{tabular}{|c|c|c|c|c|c|c|c|}
\hline \multirow{2}{*}{$\begin{array}{c}\text { Characteristics of } \\
\text { incidents of } \\
\text { psychological } \\
\text { WPV }\end{array}$} & \multicolumn{2}{|c|}{$\begin{array}{l}\text { Nurses } \\
\mathrm{N}=101\end{array}$} & \multicolumn{2}{|c|}{$\begin{array}{c}\begin{array}{c}\text { Doctors } \\
\mathrm{N}=69\end{array} \\
\end{array}$} & \multicolumn{2}{|c|}{$\begin{array}{c}\text { Total } \\
\mathbf{N}=\mathbf{1 7 0} \\
\end{array}$} & \multirow{2}{*}{$\begin{array}{c}\text { Test of } \\
\text { significance }\end{array}$} \\
\hline & $\mathbf{N}$ & $\%$ & $\mathbf{N}$ & $\%$ & $\mathbf{N}$ & $\%$ & \\
\hline \multicolumn{8}{|l|}{ The perpetrator } \\
\hline Patient & 41 & 40.6 & 27 & 39.1 & 68 & 40 & $\mathrm{MC}=1.222$ \\
\hline Relative & 56 & 55.4 & 41 & 59.4 & 97 & 57.1 & $\mathrm{P}=0.849$ \\
\hline Staff member & 3 & 3 & 1 & 1.4 & 4 & 2.4 & \\
\hline Colleague & 1 & 1 & 0 & 0 & 1 & 0.6 & \\
\hline \multicolumn{8}{|l|}{ Memory recall } \\
\hline Yes & 38 & 37.6 & 25 & 36.2 & 63 & 37.1 & $\chi 2=0.043$ \\
\hline No & 63 & 62.4 & 44 & 63.8 & 107 & 62.9 & $\mathrm{P}=0.854$ \\
\hline \multicolumn{8}{|l|}{ Avoidance } \\
\hline Yes & 38 & 37.6 & 26 & 37.7 & 64 & 37.6 & $\chi 2=0$ \\
\hline No & 63 & 62.4 & 43 & 62.3 & 106 & 62.4 & $\mathrm{P}=0.994$ \\
\hline \multicolumn{8}{|l|}{ Super alert } \\
\hline Yes & 84 & 83.2 & 61 & 88.4 & 145 & 85.3 & $\chi 2=0.897$ \\
\hline No & 17 & 16.8 & 8 & 11.6 & 25 & 14.7 & $\mathrm{P}=0.344$ \\
\hline \multicolumn{8}{|c|}{ Causes of underreporting } \\
\hline Not important & 47 & 56 & 32 & 57.1 & 79 & 56.4 & $\begin{array}{l}\chi 2=0.019 \\
P=0.889\end{array}$ \\
\hline Ashamed & 5 & 6 & 4 & 7.1 & 9 & 6.4 & $\begin{array}{l}\mathrm{FET}=0.079 \\
\mathrm{P}=1.00\end{array}$ \\
\hline $\begin{array}{l}\text { Afraid of negative } \\
\text { consequences }\end{array}$ & 20 & 23.8 & 18 & 32.1 & 38 & 27.1 & $\begin{array}{l}\chi 2=1.18 \\
P=0.277\end{array}$ \\
\hline Useless & 63 & 75 & 44 & 78.6 & 107 & 76.4 & $\begin{array}{l}\chi 2=0.238 \\
P=0.626\end{array}$ \\
\hline $\begin{array}{l}\text { Did not know who } \\
\text { to report to }\end{array}$ & 14 & 16.7 & 11 & 19.6 & 25 & 17.9 & $\begin{array}{l}\chi 2=0.203 \\
P=652\end{array}$ \\
\hline
\end{tabular}

was reported as all victims were ashamed to report such incidents, while $81.8 \%$ of them felt it was useless to report. Regarding causes of physical WPV from the perspective of included participants, table 3 demonstrated that $24 \%$ of them thought that lack of effective security measures is the main factor contributing to physical WPV. Work overload was the main trigger in the perspective of $19 \%$ of participants. More than one tenth $(14.3 \%)$ accused patients themselves for their bad morals and behaviours as a cause of violence. Moreover, another factor was shortage of staff working in the studied settings $(14.3 \%)$ with $23.4 \%$ of doctors considered it as a major trigger for WPV compared to $7.9 \%$ of nurses and this difference was statistically significant $(\mathrm{p}=$ $0.002 *)$.
As for triggers for psychological violence, table 4 showed that $21.43 \%$ of included participants reported that lack of effective security measures was a major trigger. Moreover, bad attitudes by patients, workload and overcrowding were identified as main contributing factors for psychological violence $(17 \%, 15.2 \%$ and $13.8 \%$ respectively). Ineffective security measures, as a contributing factor to psychological WPV, was significantly more reported by doctors compared to nurses $(\mathrm{p}=0.05)$

Tables 5 and 6 demonstrated that no statistically significant differences were observed between doctors and nurses in the studied settings as regard characteristics of WPV (perpetrators, psychological consequences and reporting pattern). 
Table 7: Proposed solutions to reduce incidents of WPV against HCWs.

\begin{tabular}{|c|c|c|c|c|c|c|c|}
\hline \multirow{2}{*}{$\begin{array}{l}\text { Proposed solutions } \\
\text { to reduce WPV }\end{array}$} & \multicolumn{2}{|c|}{$\begin{array}{l}\text { Nurses } \\
\mathrm{N}=113\end{array}$} & \multicolumn{2}{|c|}{$\begin{array}{c}\text { Doctors } \\
\mathrm{N}=\mathbf{8 1}\end{array}$} & \multicolumn{2}{|c|}{$\begin{array}{c}\text { Total } \\
\mathrm{N}=194\end{array}$} & \multirow{2}{*}{$\begin{array}{c}\text { Test of } \\
\text { significance }\end{array}$} \\
\hline & $\mathbf{N}$ & $\%$ & $\mathbf{N}$ & $\%$ & $\mathbf{N}$ & $\%$ & \\
\hline $\begin{array}{l}\text { Standard protocols } \\
\text { and policies against } \\
\text { WPV }\end{array}$ & 15 & 13.2 & 11 & 13.6 & 26 & 13.8 & $\begin{array}{l}\chi 2=004 \\
P=0.591\end{array}$ \\
\hline Increasing staff & 30 & 26.5 & 24 & 29.6 & 54 & 27.6 & $\begin{array}{l}\chi 2=0.223 \\
P=0.637\end{array}$ \\
\hline $\begin{array}{l}\text { Effective security } \\
\text { measures }\end{array}$ & 45 & 39.9 & 22 & 27.2 & 67 & 34.5 & $\begin{array}{l}\chi 2=3.346 \\
P=0.067\end{array}$ \\
\hline Raising awareness & 13 & 11.5 & 7 & 8.6 & 20 & 10.4 & $\begin{array}{l}\chi 2=0.418 \\
P=0.518\end{array}$ \\
\hline $\begin{array}{l}\text { Improving } \\
\text { environment }\end{array}$ & 7 & 6.2 & 6 & 7.4 & 13 & 6.9 & $\begin{array}{l}\chi 2=0.111 \\
P=0.739\end{array}$ \\
\hline Available resources & 2 & 1.8 & 5 & 6.1 & 7 & 3.4 & $\begin{array}{l}\text { FET }=2.63 \\
P=0.131\end{array}$ \\
\hline $\begin{array}{l}\text { Restriction of } \\
\text { relatives }\end{array}$ & 1 & 0.9 & 6 & 7.4 & 7 & 3.4 & $\begin{array}{l}\mathrm{FET}=5.771 \\
\mathrm{P}=0.022^{*}\end{array}$ \\
\hline
\end{tabular}

Table 7 demonstrated the proposed solutions to reduce WPV against health care providers. Nearly a third $(34.5 \%)$ of participants declared the urgent need for effective security measures. Increasing number of HCWs was another proposed measure by $27.6 \%$ of participants. Besides, the need for establishment of standard protocols and policies against violence was reported by $13.8 \%$ of included participants. Moreover, 3.4\% highlighted the importance of restricted entrance of patient relatives and it was significantly more proposed by doctors compared to nurses as an effective solution to reduce WPV $(\mathrm{p}=0.022 *)$.

\section{Discussion:}

The current study estimated that the overall prevalence of WPV was $91.7 \%$. Psychological violence was the most common form of WPV followed by physical aggression and sexual harassment $(87.6 \%, 49.5 \%$ and $12.4 \%$ respectively). These results were higher than the estimated prevalence by the American College of Emergency Physicians in 2018 (nearly half). ${ }^{16}$ Another estimated result was obtained from a recent study conducted in Hubei, China in 2018 (62.2\%) including 18.9\% and $61.4 \%$ for physical and psychological
WPV respectively. ${ }^{17}$ These differences could be explained by the nature of Egyptian community who tends to show escalating levels of violence and less respect to HCWs. Absence of strict laws and penalties against perpetrators encourage others to commit aggressive behaviours. Another factor is that the studied settings represent two of the largest emergency departments in Egypt, serving populations of at least four governorates and suffering from work overload and shortage of staff and resources.

In general, patients' relatives or companions were the main perpetrators of WPV as they were responsible for $67.7 \%$, $57.1 \%$ and $45.8 \%$ of incidents of physical, psychological and sexual WPV respectively, followed by patients themselves who were involved in $28.1 \%$, $40 \%$ and $54.2 \%$ of those incidents respectively. Patients were accused to be responsible for WPV by a Swiss Study conducted in 2018 (93\%). ${ }^{18}$ On the other hand, relatives were the main perpetrators according to a Jordanian study conducted in underserved areas in 2013 (73.9\% for physical aggression). ${ }^{19}$ The justification for this difference is that families in remote and underserved areas in Jordan 
where they tend to accompany their ill members in large numbers and could be easily triggered if the medical condition of their loved family members goes worse or if the medical care is not satisfactory.

As for psychological consequences of WPV on victims, most of them showed symptoms of Post-incident distress such as memory recall, avoidance to speak about the incident and being super-alert (54.2\%, 65.6\% and $80.2 \%$ following physical aggression, $37.1 \%, 37.6 \%$ and $85.3 \%$ following psychological abuse and $75 \%, 100 \%$ and $91.7 \%$ following sexual harassment respectively). These results were in harmony with the findings reported by Rosenthal LJ et al in 2018 who reported that following incidents of WPV, $79.7 \%$ of victims endorsed posttraumatic symptoms. ${ }^{20} \quad$ Other consequences, as observed by Schablon et al, included annoyance, fear, self-doubt, helplessness, sadness and loss of confidence. $^{21}$

Generally, the current study showed no statistical significant difference between doctors and nurses regarding exposure to physical and psychological violence and patterns of exposure. The nature and characteristics of workplace environment in the studied settings made HCWs possess similar risk of being exposed to WPV regardless of their professional role in the studied settings.

As for sexual harassment, prevalence among nurses was significantly higher than among doctors $(17.7 \%$ and $4.9 \%$ respectively). These results could be justified by the fact that most of nurses were females $(91.2 \%)$ compared to doctors who were mostly males $(84 \%)$. Another factor was that nurses had more frequent contact with patients and their relatives compared to doctors, and this made them more at risk to be sexually harassed by them.

Regarding reporting pattern of WPV, most of incidents were not reported. Physical incidents showed the highest reporting rate $(32.3 \%)$, compared to incidents of psychological violence (16.2\%), while incidents of sexual harassment were never reported. The main causes of underreporting were feeling it was useless to report, fear of bad consequences, tending to neglect the incident and feeling ashamed to report especially in case of sexual harassment. Almost similar results were observed by Abdellah et al in 2017 through a study conducted in emergency department in Ismailia, Egypt $(23.8 \%$ and $29.5 \%$ for physical and psychological WPV respectively). ${ }^{6}$ On the other hand, a much higher reporting pattern was observed by Schablon et al in $2018(85 \%){ }^{21}$ The variations in reporting patterns could be explained by supportive social and workplace environment, encouragement for reporting and presence of strict laws and penalties.

Regarding factors contributing to occurrence of WPV, the most common identified triggers were ineffective security measures, work overload and overcrowding, improper patients' attitudes and shortage of staff and resources. These findings were in agreement with the factors observed by Abu Alrub et al. (2014) ${ }^{19}$ and Ambesh $(2016)^{22}$ who categorized them into administrative factors, such as absence of effective policies and improper handling of incidents, staff factors such as shortage and poor communication skills, patients factors such as tension and previous impression of poor quality care, societal factors such as increasing levels of violence and negative image of HCWs, and security factors such as unqualified security members and increased public access.

The main solutions proposed by HCWs to tackle WPV were application of effective security measures $(34.5 \%)$, increasing staff members $(27.6 \%)$ and usage of standard protocols and policies to deal with incidents of WPV (13.8\%). In accordance with these findings, Abu Alrub et al. $(2014)^{19}$ proposed almost 
similar solutions to reduce incidents of WPV. There is no specific measure that can be relied upon lonely to tackle the rising magnitude of WPV. However, a holistic inter-disciplinary approach is required to effectively reduce these incidents. ${ }^{23}$

\section{Conclusion}

HCWs in the studied settings were exposed to considerable amounts of violence in workplace. Psychological WPV was the most common type of violence experienced by the included participants, followed by physical aggression. Relatives/companions of patients were the main perpetrators of incidents of WPV followed by patients themselves. Symptoms of Post-incident distress were obvious among the included participants following exposure to WPV. Incidents of WPV showed obvious underreporting in the studied settings. Measures against WPV require a more holistic approach rather than relying only on a specific intervention. Raising awareness, training courses and involvement of health care personnel and community gate keepers are key elements in tackling the rising epidemic of WPV together with strict policies and laws and improvement of infrastructure.

Conflicts of interests: None declared.

Source of funding: None.

\section{References}

1. Gates DM, Gillespie GL, Succop P. Violence against nurses and its impact on stress and productivity. Nursing Economics $2011 ; 29,54-69$.

2. International Labour Office ICoN, World Health Organization, Public Services International. Joint programme on workplace violence in the health sector. Workplace Violence in the Health Sector Country Case Study-Questionnaire. Geneva; 2003:14.

3. Martino VD. Workplace violence in the health sector. Country case studies Brazil B, Lebanon, Portugal, South Africa, Thailand and an additional Australian study. Ginebra.2002:49.

4. Bowie V. An emerging awareness of the role organizational culture and management style can play in triggering workplace violence. Workplace Violence in the Mental and General Healthcare Setting. 2010 Oct 25;1:43-58.

5. Kvas A, Seljak J. Unreported workplace violence in nursing. International nursing review. 2014 Sep 1;61(3):344-51.

6. Abdellah RF,Salama KM.Prevalence and risk factors of workplace violence against health care workers in emergency department in Ismailia, Egypt. Pan Afr Med J 2017; 26: 21.

7. Saad KR. Workplace bullying and harassment among nurses in Alexandria Main University Hospital. Faculty of Medicine Alexandria University. 2018. p 38.

8. American College of Emergency Physicians. American College of Emergency Physicians - fact sheets. [Online]. Available at: $\quad$ http://newsroom.acep.org/fact sheets?item530010. [Last access March 2019].

9. Emergency Nurses Association. Emergency department violence surveillance study. Des Plaines, IL: Emergency Nurses Association. 2011 Nov.

10. Kowalenko T, Gates D, Gillespie GL, Succop P, Mentzel TK. Prospective study of violence against ED workers. AJEM 2013;31:197-205.

11. Di Martino V. A cross-national comparison of workplace violence and response strategies. Chap. 2005 Oct 1;2:1536.

12. Farrell GA, Bobrowski C, Bobrowski P. Scoping workplace aggression in nursing: findings from an Australian study. Journal of advanced nursing. 2006 Sep 1;55(6):778-87. 13. Vessey JA, Demarco R, DiFazio R. Bullying, harassment, and horizontal violence in the nursing workforce: the state of the science. Annu Rev Nurs Res 2010; 28:13357.

14. Wyatt R, Anderson-Drevs K, Van Male LM. Workplace violence in health care: a critical issue with a promising solution. JAMA. 2016 Sep 13;316(10):1037-8.

15. World Health Organization. violence against health workers [Online].2003. Available from http://www.who.int/violence_injury_preventi 
on/violence/workplace/en/. [Last access March 2019].

16. American College of Emergency Physicians. American College of Emergency Physicians. workplace violence prevention letter of support. [Online]. available from https://www.acep.org/globalassets/newpdfs/advocacy/acep---workplace-violenceprevention-letter- of-support.pdf [Last accessed August 2019].

17. Gan Y, Li L, Jiang H, Lu K, Yan S, Cao $\mathrm{S}, \mathrm{Fu} \mathrm{W}, \mathrm{Hu} \mathrm{S}$, Qiao Y, Yang T, Wang C. Prevalence and risk factors associated with workplace violence against general practitioners in Hubei, China. American journal of public health. 2018 Sep;108(9):1223-6.

18. Kaeser D, Guerra R, Keidar O, Lanz U, Moses M, Kobel C, Exadaktylos A, Ricklin $\mathrm{M}$. Verbal and non-verbal aggression in a Swiss university emergency room: a descriptive study. International journal of environmental research and public health. 2018 Jul 6;15(7):1423.
19. AbuAlRub RF, Al Khawaldeh AT. Workplace physical violence among hospital nurses and physicians in underserved areas in J ordan. Journal of clinical nursing. 2014 Jul;23(13-14):1937-47.

20. Rosenthal LJ, Byerly A, Taylor AD, Martinovich Z. Impact and Prevalence of Physical and Verbal Violence Toward Healthcare Workers. Psychosomatics. 2018 May 9.

21. Anja Schablon, Dana Wendeler, Agnessa Kozak, Albert Nienhaus, Susanne Steinke. Prevalence and Consequences of Aggression and Violence towards Nursing and Care Staff in Germany-A Survey. International Journal of Environmental Research and Public Health. .

22. Ambesh P. Violence against doctors in the Indian subcontinent: A rising bane. Indian heart journal. 2016 Sep 1;68(5):749-50.

23. BK Fasanya. Workplace Violence and Safety Issues in Long-Term Medical Care Facilities: Nurses' Perspectives. 2015 Dec 1; Available at: https://www.ncbi.nlm.nih.gov 